\title{
Dual Role of Thyroid Hormones in Rat Soleus Muscle MyHC Isoform Expression
}

\author{
A. VADÁSZOVÁ-SOUKUP, T. SOUKUP \\ Institute of Physiology, Czech Academy of Sciences, Prague, Czech Republic
}

Received July 10, 2007

Accepted October 30, 2007

\begin{abstract}
Summary
We have analyzed the influence of altered thyroid hormone levels on changes of $\mathrm{MyHC}$ protein isoforms and their $m R N A$ transcripts in the soleus muscle of 2-, 4- and 7-month-old euthyroid (EU), hypothyroid (HY) and hyperthyroid (TH) female inbred Lewis strain rats (methimazole and $\mathrm{T}_{3}$ treatment started 3 to 4 weeks after birth). We have found that the content of the dominant MyHC 1 isoform gradually increased in the EU rats and that this increase was more progressive in the HY rats at all three stages. On the other hand, in the TH rats the content of MyHC 1 isoform was the highest in the 2-month-old rats and it decreased with an increasing length of $\mathrm{T}_{3}$ treatment. The content of the minor $2 \mathrm{a}$ $\mathrm{MyHC}$ isoform followed the opposite pattern. In contrast to the protein isoforms, the MyHC $m R N A$ transcripts remained at similar levels. Nevertheless, in general, the MyHC $1 m R N A$ level was decreased and MyHC 2a transcript increased in the TH rats, while the opposite changes occurred in the HY rats. Our results thus suggest that in the rat soleus muscle, both increased and decreased levels of thyroid hormones speed up the formation of an adult slow phenotype which is demonstrated by the precocious appearance of the slow MyHC 1 isoform, but opposite to the hypothyroid status, a longer $\mathrm{T}_{3}$ application promotes the expression of the faster MyHC 2a isoform.
\end{abstract}

\section{Key words}

Rat development $\bullet$ Soleus muscle $\bullet$ Myosin heavy chains $\bullet$ Thyroid hormones $\bullet$ SDS-PAGE $\bullet$ RT-PCR

\section{Introduction}

The soleus is a slow antigravity muscle consisting of a majority of slow type 1 fibers in adult rats, supplemented by a small number of fast $2 \mathrm{~A}$ fibers. Thyroid hormones strongly influence the fiber type composition and the MyHC content during the development, regeneration or even in adult rats (Soukup and Jirmanová 2000). At 2 months, the level of 3,3',5triiodo-L-thyronine $\left(\mathrm{T}_{3}\right)$ slightly declines, compared to a peak level present at 2 weeks, to a plateau typical for the adult rat (Dubois and Dussault 1977). It was shown that the hyperthyroid rats display an earlier switching from an perinatal to adult-type $\mathrm{MyHC}$ isoforms and that the hyperthyroid status leads to a preferential expression of fast MyHC isoforms, while the contrary holds true for hypothyroid rats. Regarding the soleus muscle, these two facts are partly in contradiction, as the hyperthyroid status should speed up the establishment of the adult pattern, characterized by the prevalence of the slow MyHC 1, but 
concomitantly it should lead to the preferential expression of the fast 2a MyHC isoform. We have therefore analyzed changes of the MyHC isoform content and $m R N A$ transcript levels in the soleus muscle of the 2-, 4and 7-month-old euthyroid (EU), hypothyroid (HY) and hyperthyroid $(\mathrm{TH})$ rats.

Pregnant female inbred Lewis strain rats were obtained from the authorized laboratory rat-breeding unit of the Institute of Physiology (Accreditation No. 1020/491/A/00). The maintenance and handling of the experimental animals was in accordance with EU Council Directive (86/609EEC) and the investigation was approved by the Expert Committee of the Institute of Physiology, Academy of Sciences, Prague, Czech Republic. The hypothyroid status (HY) was induced and maintained with a $0.05 \%$ solution of methimazole (2-Mercapto-1- methylimidazole, Sigma) in drinking water, the hyperthyroid status $(\mathrm{TH})$ by intraperitoneal injections of 3, 3',5-triiodo-L-thyronine (Sigma, sodium salt, $\mathrm{T}_{3}, 150 \mu \mathrm{g} / \mathrm{kg}$ body weight) 3 times a week, both applications starting 3-4 weeks after birth. The changes of the thyroid status have been confirmed by ELISA measurements of total $\mathrm{T}_{3}$ and $\mathrm{T}_{4}$ serum levels and of body, heart and thyroid gland weights (cf. Soukup et al. 2001). Muscles, excised from the 2-, 4- and 7-month-old female rats, were collected after anesthesia by Nembutal (sodium pentobarbital, $40 \mathrm{mg} / \mathrm{kg}$, i.p.), frozen in liquid nitrogen and processed for SDS-PAGE and RT-PCR.

MyHC isoforms were separated by sodium dodecyl sulphate-polyacrylamide gel electrophoresis (SDS-PAGE) (Talmadge and Roy 1993) carried out at constant voltage $(70 \mathrm{~V})$ for $30 \mathrm{~h}$ at $4{ }^{\circ} \mathrm{C}$ (Zachařová et al. 2005). The gels were silver-stained (Blum et al. 1987) and individual bands were densitometrically evaluated using Quantity One program (Bio-Rad Laboratories) or AIDA 3.28 computer program (Advanced Image Data Analyzer, Germany). The $m R N A$ levels of MyHC isoforms were quantified using reverse transcription and polymerase chain reaction (RT-PCR) relatively to the housekeeper glyceraldehyde-3-phosphate dehydrogenase (GAPDH) as described before (Vadászová et al. 2006a,b). The amplified fragments were evaluated on $2 \%$ agarose gels and the optical density per $\mathrm{mm}^{2}$ of each fragment was measured using PCBAS software (Hudecová et al. 2004). The data are expressed as means \pm S.D. and the significance $(\mathrm{p}<0.05)$ was evaluated with the Student's T-test.

The type $1 \mathrm{MyHC}$ isoform predominated already in the 2-month-old rats in all thyroid states (Figs 1 and 2).

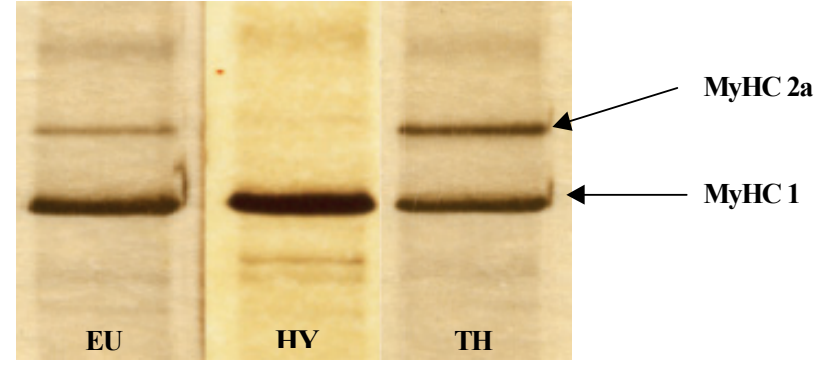

Fig. 1. Electrophoretic separation of MyHC isoforms in the soleus muscles of 7-month-old female euthyroid (EU), hypothyroid (HY) and hyperthyroid $(\mathrm{TH})$ rats of the inbred Lewis strain. The type 1 and $2 \mathrm{a} \mathrm{MyHC}$ bands are labeled.

In the 2-month-old EU rats we have found $67.8 \pm 14.2 \%$ of the MyHC 1, whereas in the HY 2-month-old rats the MyHC 1 content increased to $75.9 \pm 5.0 \%(\mathrm{p}<0.05$ compared to EU ones) and in the TH rats of the same age even to $92.2 \pm 2.2 \%$ ( $p<0.001$ compared to EU ones) of the slow type $1 \mathrm{MyHC}$ isoform. With increasing age, the content of the MyHC 1 isoform increased by $19.8 \%$ and $30.7 \%$ in the 4- and 7-month-old EU animals, respectively, compared to the 2-month-old ones (Fig. 2). In the HY rats, the MyHC 1 content also increased, by $18.9 \%$ and $22.9 \%$, respectively, compared to their 2month-old HY littermates (Fig. 2). On the other hand, in the TH rats, the content of the MyHC 1 isoform gradually decreased by $6.2 \%$ and $21.0 \%$ in the 4 - and 7 -month-old rats, respectively, compared to the 2-month-old $\mathrm{TH}$ animals (Fig. 2). The content of the MyHC 1 isoform in the 2-month-old TH rats was comparable to that found in the 4-month-old EU and $\mathrm{HY}$ ones. Although the percentage of the MyHC 1 isoform in the 4-month-old EU or HY and TH animals was similar (apparently just by chance at this age), it was a result of two opposite processes: in the EU rats, as well as in the HY ones, the MyHC 1 content was permanently increasing, while in the TH rats it was gradually decreasing. Therefore, in the 7-month-old rats, while the content of the MyHC 1 reached the peak of almost $99 \%$ in the EU and HY rats, in the TH animals its content decreased to $71.2 \%$ (p < 0.01 compared to EU and HY rats).

Using RT-PCR we have found in the soleus muscle all four $(1,2 \mathrm{a}, 2 \mathrm{x} / \mathrm{d}$ and 2b) MyHC $m R N A$ transcripts (see also Vadászová et al. 2006a), similarly as in the EDL muscle (Vadászová et al. 2006b). In contrast to the significant changes of the MyHC 1 and 2a protein isoforms during the experimental period, the expression of the mRNA transcripts remained at similar levels. However, our data have shown a significantly decreased 


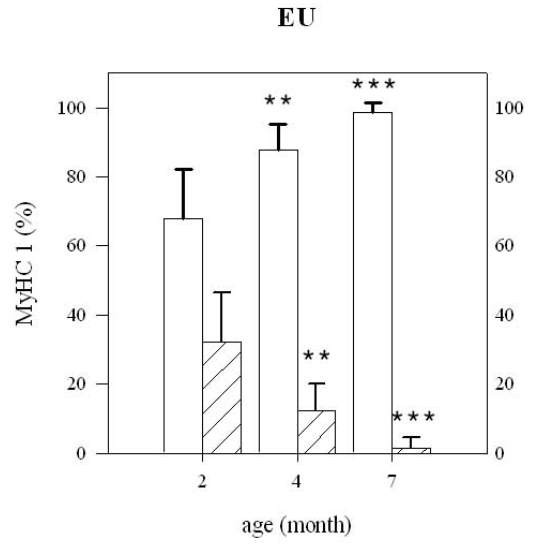

HY

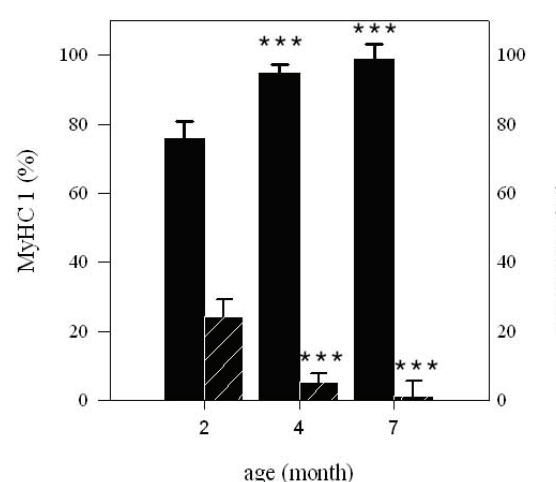

TH

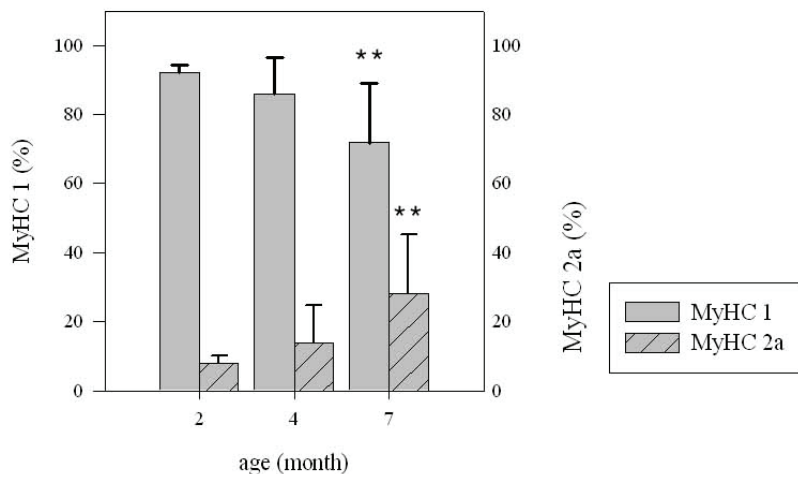

Fig. 2. Histogram of mean levels of the MyHC1 and $2 a$ isoforms expressed as the percentage of their total content in the soleus muscles from 2-, 4- and 7-month-old euthyroid (EU), hypothyroic (HY) and hyperthyroid (TH) female inbred Lewis strain rats $* * p<0.01, * * * p<0.001$ significant differences against the 2 . month-old rats. The number of muscles measured was 10,4 anc 16 in the 2-, 4- and 7-month-old EU rats, respectively, 4-, 4- anc 11- in the HY rats and 4-, 4- and 8 in the TH rats. Data for the $2 \bar{c}$ $\mathrm{MyHC}$ in the 2-month-old HY rats include also a small percentage of the $2 x / d$ and $2 b$ isoforms.

level of the 2a transcript in the HY and an increased one in the $\mathrm{TH}$ rats compared to the EU animals, as well as a significantly lower level of the MyHC 1 and an increased 2a $m R N A$ transcript level in the TH compared to the HY
Table 1. Expression of $m R N A$ MyHC isoform transcripts (arbitrary units $x$ 10) in the soleus muscles of adult euthyroid (EU), hypothyroid (HY) and hyperthyroid (TH) female inbred Lewis strain rats (pooled data from the 2-, 4- and 7-month-old rats), $\mathrm{n}=$ number of muscles measured, ${ }^{*} \mathrm{p}<0.05$ significant difference between the $\mathrm{HY}$ or $\mathrm{TH}$ and $\mathrm{EU}$ rats, ${ }^{+} \mathrm{p}<0.05$ significant difference between the $\mathrm{TH}$ and $\mathrm{HY}$ rats.

\begin{tabular}{ccccc}
\hline $\begin{array}{c}\text { Thyroid } \\
\text { status }\end{array}$ & MyHC 1 & \multicolumn{4}{c}{ MyHC 2a } & MyHC 2x & MyHC 2b \\
\hline$E U n=12$ & $12.7 \pm 4.8$ & $3.4 \pm 3.1$ & $7.4 \pm 2.7$ & $3.9 \pm 4.3$ \\
$H Y n=7$ & $16.1 \pm 2.7^{+}$ & $1.5 \pm 2.3^{\#+}$ & $7.0 \pm 5.1$ & $4.9 \pm 3.4$ \\
$T H n=7$ & $9.1 \pm 4.9^{+}$ & $6.6 \pm 4.7^{\#+}$ & $6.2 \pm 3.5$ & $2.8 \pm 4.6$ \\
\hline
\end{tabular}

rats (Table 1). The content of the type $1 \mathrm{MyHC} m R N A$ transcript was about $25 \%$ higher in the HY rats and about $25 \%$ lower in the TH rats, compared to the EU animals. Similarly, the percentage of the 2a MyHC $m R N A$ transcript decreased by about half in the HY and doubled in the TH rats in comparison with their EU littermates. Levels of transcripts for 2x/d and $2 \mathrm{~b}$ MyHC isoforms did not change significantly according to the thyroid status. These results fit with differences described earlier in a smaller sample of 7-month-old rats (Vadászová et al. 2006a). The observed difference between changes at the protein and $m R N A$ levels suggest that in the chronic experiments (especially in the case of structural proteins with a long half life, like MyHC isoforms), minor changes of the $m R N A$ level transcripts can eventually result in major changes at the protein level.

Skeletal muscles of small rodents contain four main fiber types, namely type 1,2A, 2X/D and 2B fibers containing MyHC 1, 2a, 2x/d and $2 b$ isoforms and thyroid hormones exert their effects largely by influencing the transcriptional control of the MyHC gene expression (for review see Schiaffino and Reggiani 1996, Pette 2002). The thyroid hormones induce the expression of a MyHC isoform of higher ATPase activity, in the slow soleus muscle the expression of the $2 \mathrm{a}$ MyHC isoform is increased together with the muscle contraction velocity; in the fast muscles, like EDL, containing all three fast 2a, 2x/d and 2b MyHC isoforms, the $2 \mathrm{~b} \mathrm{MyHC}$, which has the highest ATPase activity, is favored. Similarly as in our rats, the hyperthyroidism increased the contractile velocity in the adult female Sprague-Dawley rat soleus and decreased the proportion of the slow MyHC 1 from $93 \%$ to $69 \%$ (Caiozzo et al. 1991). Decreased $\mathrm{T}_{3}$ levels in HY rats have less "visible" effects on $\mathrm{MyHC}$ composition in the soleus muscle, as they favor 
the dominating MyHC 1 isoform. Nevertheless, our results show that the $\mathrm{HY}$ status speeds up and strengthens the naturally occurring increase of the MyHC 1 isoform content during a postnatal development. In contrast to the TH status, decreased levels of thyroid hormones have the same effect in all three age groups, as they increase the percentage of the slow MyHC 1 isoform in 2-, 4- and 7month-old rats compared to EU littermates.

From our results we can conclude that in the rat soleus muscle both increased and decreased levels of thyroid hormones speed up the formation of an adult slow phenotype in 2-month-old rats, which is demonstrated by the precocious appearance of the slow MyHC 1 isoform.

Furthermore, the increased levels of thyroid hormones can play the "dual" role changing with time, as in the 2-month-old $\mathrm{TH}$ rats (i.e. after about one month of the $\mathrm{T}_{3}$ treatment) thyroid hormones, in agreement with their role in development, speed up the formation of an adult slow phenotype, but after three and six months of the $\mathrm{T}_{3}$ treatment they promote the expression of the faster 2a MyHC isoform, which is in agreement with their effect in adult rats.

\section{Acknowledgements}

We are obliged to Prof. O. Križanová and Ing. S. Hudecová for their help during RT-PCR measurements. Supported by MYORES No. 511978, MŠMT ČR LC554, GAČR 304/05/0327 grants and by the Research project AV0Z 50110509.

\section{References}

BLUM H, BEIER H, GROSS HJ: Improved silver staining of plant proteins, RNA and DNA in polyacrylamide gels. Electrophoresis 8: 93-99, 1987.

CAIOZZO VJ, HERRICK RE, BALDWIN KM: Influence of hyperthyroidism on maximal shortening velocity and myosin isoform distribution in skeletal muscle. Am J Physiol 261: C285-C295, 1991.

DUBOIS JD, DUSSAULT JH: Ontogenesis of thyroid function in the neonatal rat. Thyroxine $\left(\mathrm{T}_{4}\right)$ and triiodothyronine $\left(\mathrm{T}_{3}\right)$ production rates. Endocrinology 101: 435-441, 1977.

HUDECOVÁ S, VASDÁSZOVÁ A, SOUKUP T, KRIŽANOVÁ O: Effect of thyroid hormones on the gene expression of calcium transport systems in rat muscle. Life Sci 75: 923-931, 2004.

PETTE D: The adaptive potential of skeletal muscle fibers. Can J Appl Physiol 27: 423-448, 2002.

SCHIAFFINO S, REGGIANI C: Molecular diversity of myofibrillar proteins: gene regulation and functional significance. Physiol Rev 76: 371-423, 1996.

SOUKUP T, JIRMANOVÁ I: Regulation of myosin expression in developing and regenerating extrafusal and intrafusal muscle fibres with special emphasis on the role of thyroid hormones. Physiol Res 49: 617-633, 2000.

SOUKUP T, ZACHAŘOVÁ G, SMERDU V, JIRMANOVÁ I: Body, heart, thyroid gland and skeletal muscle weight changes in rats with altered thyroid status. Physiol Res 50: 619-626, 2001.

SOUKUP T, ZACHAŘOVÁ G, SMERDU V: Fibre type composition of soleus and extensor digitorum longus muscles in normal female inbred Lewis rats. Acta Histochem 104: 399-405, 2002.

TALMADGE RJ, ROY RR: Electrophoretic separation of the rat skeletal muscle myosin heavy-chain isoforms. $J$ Appl Physiol 75: 2337-2340, 1993.

VADÁSZOVÁ A, HUDECOVÁ S, KRIŽANOVÁ O, SOUKUP T: Levels of myosin heavy chain mRNA transcripts and content of protein isoforms in the slow soleus muscle of 7-month-old rats with altered thyroid status. Physiol Res 55: 221-225, 2006a.

VADÁSZOVÁ A, HUDECOVÁ S, KRIŽANOVÁ O, SOUKUP T: Levels of myosin heavy chain mRNA transcripts and protein isoforms in the fast extensor digitorum longus muscle of 7-month-old rats with chronic thyroid status alterations. Physiol Res 55: 707-710, 2006 b.

ZACHAŘOVÁ G, VADÁSZOVÁ A, SMERDU V, ASMUSSEN G, SOUKUP T: The effect of a unilateral muscle transplantation on the muscle fiber type and the MyHC isoform content in unoperated hind limb slow and fast muscles of the inbred Lewis rats. Physiol Res 54, 691-696, 2005.

\section{Corresponding author}

T. Soukup, Institute of Physiology, Czech Academy of Sciences, Vídeňská 1083, CZ-142 20 Prague, Czech Republic. Fax: +420 24106 2488. E-mail: tsoukup@biomed.cas.cz 